\title{
An Sfp-Type PPTase and Associated Polyketide and Nonribosomal Peptide Synthases in Agrobacterium vitis Are Essential for Induction of Tobacco Hypersensitive Response and Grape Necrosis
}

\author{
Desen Zheng and Thomas J. Burr \\ Department of Plant Pathology and Plant-Microbe Biology, New York State Agricultural Experimental Station, Cornell \\ University, 630 W. North Street Geneva, NY 14456, U.S.A.
}

Submitted 20 December 2012. Accepted 25 March 2013.

\begin{abstract}
An Sfp-type phosphopantetheinyl transferase (PPTase) encoding gene $F$-avi5813 in Agrobacterium vitis F2/5 was found to be required for the induction of a tobacco hypersensitive response (HR) and grape necrosis. Sfp-type PPTases are post-translation modification enzymes that activate acyl-carry protein (ACP) domains in polyketide synthases (PKS) and peptidyl-carrier protein (PCP) domains of nonribosomal peptide synthases (NRPS). Mutagenesis of PKS and NRPS genes in $A$. vitis led to the identification of a PKS gene ( $F$-avi4330) and NRPS gene $(F$ avi3342) that are both required for $H R$ and necrosis. The gene immediately downstream of $F$-avi4330 (F-avi4329) encoding a predicted aminotransferase was also found to be required for $H R$ and necrosis. Regulation of $F$-avi4330 and $F$-avi3342 by quorum-sensing genes $a v h R$, aviR, and avsR and by a lys $R$-type regulator, lhnR, was investigated. It was determined that $F$-avi4330 expression is positively regulated by $a v h R$, aviR, and $l h n R$ and negatively regulated by avs $R$. F-avi3342 was found to be positively regulated by $a v h R$, aviR, and $a v s R$ and negatively regulated by $l h n R$. Our results suggest that a putative hybrid peptide-polyketide metabolite synthesized by $F$-avi4330 and $F$-avi3342 is associated with induction of tobacco HR and grape necrosis. This is the first report that demonstrates that NRPS and PKS play essential roles in conferring the unique ability of $A$. vitis to elicit a non-host-specific HR and hostspecific necrosis.
\end{abstract}

Agrobacterium vitis is a host-specific plant pathogen that causes crown gall of grape affecting vine growth and production worldwide (Burr and Otten 1999). A. vitis possesses unique features compared with other Agrobacterium spp.; both tumorigenic and nontumorigenic strains cause a host- and tissue-specific necrosis on grape (Burr et al. 1987) and a hypersensitive response (HR) when infiltrated into leaf panels of nonhost plants such as tobacco (Herlache et al. 2001). Grape necrosis is most evident on certain tissues such as young grape

Corresponding author: T. J. Burr; E-mail: tjb1@ cornell.edu; Telephone: +1.315.787.2211; Fax: +1.315.787.2389

*The $\boldsymbol{e}$-Xtra logo stands for "electronic extra" and indicates Figures 1 through 6 appear in color online.

(C) 2013 The American Phytopathological Society roots. Grape necrosis may play roles in survival of the bacterium in soil and in invasion into grapevines (Burr et al. 1987). HR has been shown to represent a defense response of plants against pathogen attack. Several HR elicitor proteins produced by plant-pathogenic bacteria have been identified and are generally delivered to plants via the type III secretion system (T3SS) (Büttner and He 2009). No hrp gene clusters or a T3SS have been found in the genome of $A$. vitis strain $\mathrm{S} 4$. Therefore, it appears that the HR and necrosis caused by A. vitis are T3SS independent.

We previously reported several genes in A. vitis strain F2/5 involved in HR and necrosis, including quorum-sensing-associated luxR homologs (aviR, avhR, and avsR), one luxI homo$\log$ (autoinducer synthase), avsI (Hao and Burr 2006; Hao et al. 2005; Zheng et al. 2003), and an lysR-type transcriptional regulator gene, $l h n R$, and an upstream operon, $\operatorname{lhnABC}$ (Zheng et al. 2012). In addition, a type I polyketide synthase (PKS) gene cluster was found to be associated with but not absolutely required for HR and necrosis (Carle 2008). To further elucidate the role of PKS and related genes in HR and necrosis, we initially investigated genes encoding phosphopantetheinyl transferases (PPTases). PPTases belong to a superfamily of post-translational modification enzymes that have been divided into two types based on gene structure and substrate specificity (Lambalot et al. 1996). The first are AcpS-type enzymes, consisting of 120 to 140 amino acids that are involved in fatty acid biosynthesis; and the second are Sfp-type enzymes, 220 to 240 amino acids in length, which participate in biosynthesis of secondary metabolites by activating the peptidyl-carrier protein (PCP) domain of the nonribosomal peptide synthetase (NRPS) and acyl carrier protein (ACP) domain of PKS (Lambalot et al. 1996; Walsh et al. 1997). In preliminary experiments, disruption of a gene encoding a putative Sfp-type PPTase resulted in HR- and necrosis-negative phenotypes, suggesting the presence of a PKS or NRPS required for these phenotypes. PKS and NRPS share architectural and organizational similarities and catalyze the biosynthesis of polyketides or nonribosomal peptides and peptide-polyketide hybrid molecules in bacteria and fungi. Polyketides and nonribosomal peptides are two large families of secondary metabolites with structural complexities that have diverse biological activities and pharmacological properties (Cane and Walsh 1999; Gokhale et al. 2007; Hertweck 2009; Schwarzer et al. 2003). Among the known polyketides and nonribosomal peptides, a number of them produced by phytopathogenic bacteria have phytotoxin, antibiotic activities, or both. For example, coronatine from Pseudomonas 
syringe, a non-host-specific phytotoxin, is an important virulence factor (Bender et al. 1999) consisting of the polyketide coronafacic acid and the cyclized amino acid coronamic acid, which are synthesized by PKS and NRPS individually and coupled into a hybrid polyketide-amino acid metabolite by a discrete ligase (Du et al. 2001). Another example, albicindin produced by the sugarcane leaf scald pathogen Xanthomonas albilineans, is a phytotoxin that blocks DNA replication in chloroplasts (Birch and Patil 1987) and shows antibiotic activity to a range of gram-positive and gram-negative bacteria (Birch and Patil 1985). Albicidin is synthesized by PKS-NRPS hybrid enzymes and a number of modifying enzymes (Huang et al. 2001; Royer et al. 2004). There are no reports of polyketide, nonribosomal peptide, or polyketide-peptide hybrid molecules or derivatives being involved in plant HR induction. From mining the genome sequence of $A$. vitis strain S4, we identified three PKS and two NRPS genes in chromosomes that were also found present in strain F2/5 by polymerase chain reaction (PCR) analyses.

In this article, we report the identification, organization, and regulation of genes encoding PPTase, PKS, and NRPS in A. vitis genome and elucidate their role in HR and necrosis induction.

\section{RESULTS}

An Sfp type PPTase in $A$. vitis is associated with induction of $H R$ and grape necrosis.

Two PPTase gene homologs were identified in the A. vitis S4 genome. One (avi9644) resides on plasmid P130 and another (avi5813) on chromosome II. A PCR analysis indicated that only avi5813 is present in strain F2/5 and was designated as $F$-avi5813; no sequence corresponding to avi 9644 was identified in F2/5. The organization of $F$-avi5813 in F2/5 relative to surrounding genes is shown in Figure 1A, and is the same as in S4. Its deduced sequence includes 244 amino acid residues having $97.5 \%$ sequence identity to avi5813. F-avi5813 also shares identity with the PPTase gene (ZP_09284730) from $P$. psychrotolerans L19 (35.7\%) and with EGH96826 from $P$. syringae pv. lachrymans M302278 (33.2\%). Sequence identity between $F$-avi5813 and PPTase (Atu_4416) in A. tumefaciens C58 is $30.8 \%$ and the identities between $F$-avi58213 and those from other sequenced Rhizobiaceae are lower. Based on the gene size and sequence similarity, $F$-avi5813 belongs to the Sfp-type PPTase group. Mutant of $F$-avi5813 was generated by insertion of vector pVIK165 sequence through a single homologous recombination region comprising amino acid residues 24 to 162 . Disruption of $F$-avi5813 did not affect F2/5 growth in media; however, it resulted in the loss of capacity to cause tobacco HR and grape necrosis (Fig. 1B). Complementation of the $F$-avi5813 mutant restored the HR and necrosis phenotypes (Fig.1 B). From these results, we predicted that $F$-avi5813 is involved in biosynthesis of polyketides and nonribosomal peptides that are required for grape necrosis and tobacco HR.

\section{Identity of PKS and NRPS genes and their effects on HR and necrosis.}

Two NRPS and three PKS gene homologs were identified on chromosome I and chromosome II of strain S4. Based on PCR analyses, all five genes were also present in F2/5. Two of the PKS genes, $a v h E$ and $a v h F$, (corresponding to avi5624 and avi5625, residing within a gene cluster on chromosome II of S4) have been characterized previously by our lab (Carle et al. 2008) and found to be associated with but not absolutely required for HR and necrosis. Therefore, two NRPS genes $(F$-avi5730 and $F$-avi3342) and one PKS gene $(F$-avi4330) in F2/5 were mutagenized by gene disruption. The $F$-avi5730 (residing on chromosome II) mutant did not affect tobacco HR and grape necrosis
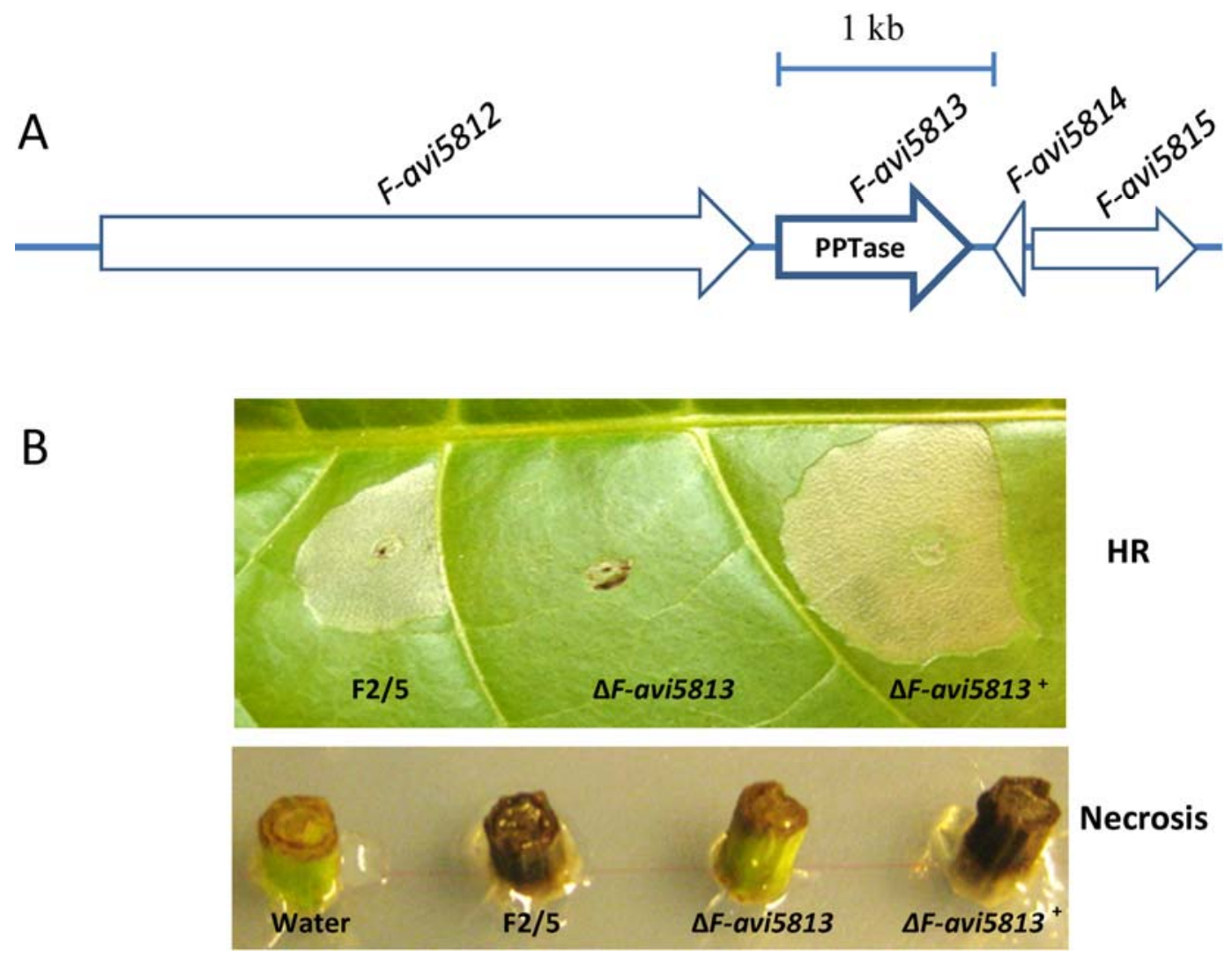

Fig. 1. A, Organization of F-avi5813 phosphopantetheinyl transferase (PPTase) and flanking genes and B, tobacco hypersensitive response (HR) and necrosis of grape shoot explants caused by $\mathrm{F} 2 / 5$, mutant $\Delta F$-avi5813, and complemented mutant $\Delta F$-avi $5813^{+}$. 
whereas F-avi3342 and F-avi4330, both residing on chromosome I, were required for expression these phenotypes.

F-avi3342 comprises 4,005 bp and encodes a polypeptide with 1,334 amino acid residues. The deduced sequence contains condensation (C), adenylation (A), PCP, and thio-esterase domains in a single module of NRPS (Fig. 2A). It shares $99 \%$ identity with avi3342 from S4 and is similar (61\% identity) to the NRPS gene (Arad_8972) from A. radiobacter K84, and 46\% with YP_693504 from Alcanivorax borkumensis. The A domain of an NRPS is responsible for recognition of a specific substrate (amino acid or hydroxyl acid) and activates it as its aminoacyl adenylate. The specificity-conferring amino acid residues (signature) of the A domain in NRPS have been identified based on the analysis of crystal structure of gramicidin $S$ synthetase-1 (GrsA) (Conti et al. 1997). General rules for deducing substrate specificity of the A domain in an NRPS have been developed by comparing the signature with GrsA (Stachelhaus et al. 1999). The signature of $F$-avi3342 has been identified and the A domain is predicted to be glycine activat- ing according to signature comparison with other glycine-activating NRPS (Fig. 2B). F-avi3342 was mutagenized by interruption of the sequence encoding the 134th to 334th amino acid residues. The mutant does not induce tobacco HR and grape necrosis (Fig. 2C). Therefore, F-avi3342 encodes a putative NRPS that is required for tobacco HR and grape necrosis.

The organization of $F$-avi4330 and flanking genes is shown in Figure 3A. F-avi4330, which shares $98 \%$ identity with avi4330 from $\mathrm{S} 4$, is a predicted PKS gene that consists of $7,572 \mathrm{bp}$ and encodes a polypeptide of 2,523 amino acid residues. It contains keto-synthase, acyltransferase (AT), dehydratase (DH), enoylreductase, ketoreductase, and ACP domains. The two immediate downstream genes, $F$-avi4329 and $F$ avi4328, that are co-transcribed as a operon according to reverse-transcription PCR analysis (results not shown), encode a putative aminotransferase protein and a short-chain dehydrogenase protein, respectively according to genome annotation. $F$-avi4330, $F$-avi4329, and $F$-avi4328 are similar in sequence and structure to $r k p \mathrm{~A}, r k p \mathrm{G}$, and $r k p \mathrm{H}$, respectively, in the $r k p-1$

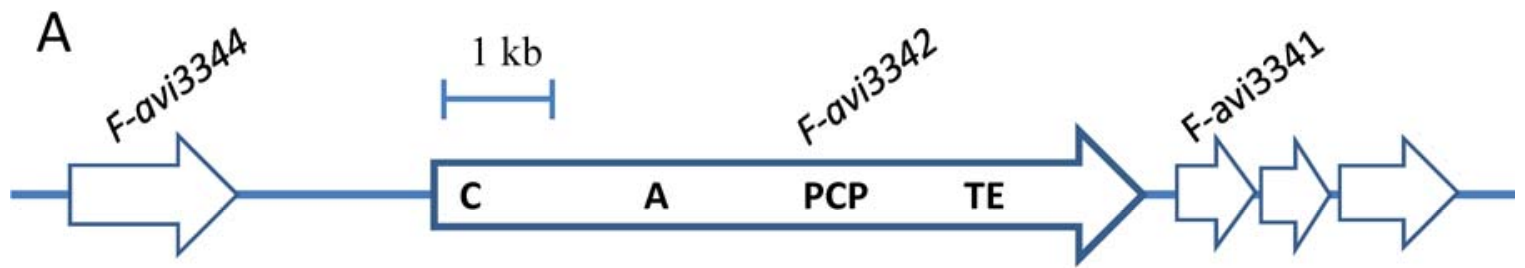

\begin{tabular}{|c|c|c|c|}
\hline $\begin{array}{l}\text { A-domain } \\
\text { of NRPS }\end{array}$ & Signature of NRPS & $\frac{\text { Amino acid }}{\text { Predicted Substrate }}$ & Reference \\
\hline GraA & D A W T I A A I K & Phe & Stachelhaus et al. 1999 \\
\hline DhbF1 & D I L Q I G I I W K & Gly & May et al. 2001 \\
\hline F-avi3342 & D I L $Q I G V I W K$ & Gly & This work \\
\hline SafA-1 & D I L \& I G I I W K & Gly & Du et al. 2000 \\
\hline Tal & D I L $Q I G M I W K$ & Gly & Du et al. 2000 \\
\hline CdaPSII-2 & D I I $Q I G I I W K$ & Gly & Du et al. 2000 \\
\hline
\end{tabular}

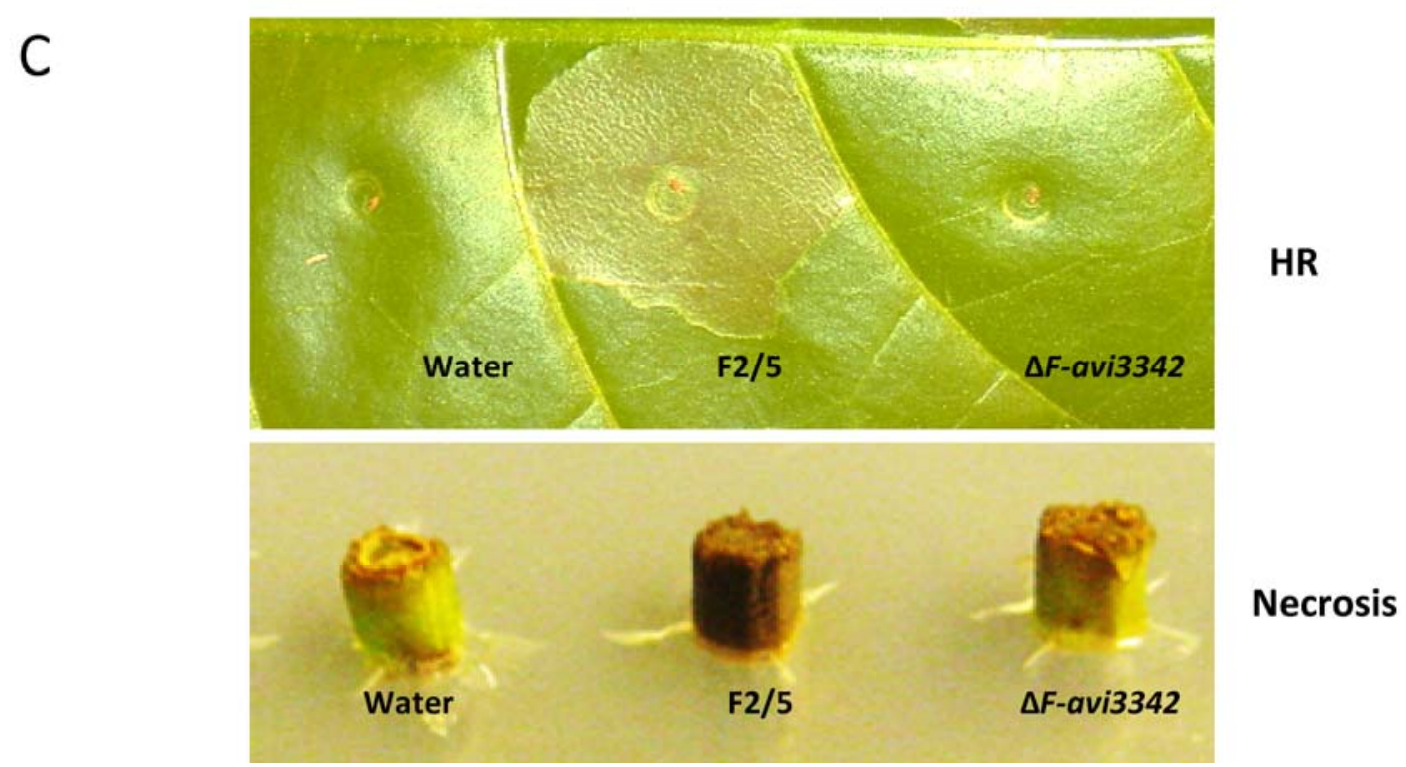

Fig. 2. A, Organization of F-avi3342 and flanking genes; B, comparison of A-domain signature and prediction of amino acid activated by F-avi3342; and $\mathbf{C}$, tobacco hypersensitive response (HR) and necrosis of grape shoot explants caused by F2/5, mutant $\Delta F$-avi3342, and complemented mutant $\Delta F$-avi3342 . 
region of Sinorhizobium fredii $\mathrm{HH} 103$ and S. meliloti 1021 (Fig. 3A). The similarities of deduced sequences between $F$ avi4330, F-avi4329, and $F$-avi4328 and $r k p \mathrm{~A}, r k p \mathrm{G}$, and $r k p \mathrm{H}$ are 58, 63, and 49\%, respectively. To generate the $F$-avi4330 mutant, vector pVIK 165 was inserted at the coding region of the 69th to 311th amino acid residues, and the flanking genes F-avi4331, F-avi4329, and F-avi4328 were also individually mutated and tested for ability to cause tobacco HR and grape necrosis. The $F$-avi4331 and $F$-avi4328 mutants did not affect either phenotype whereas the $F$-avi4330 and $F$-avi4329 mutants were HR and necrosis minus (Fig. 3B). The $F$-avi4329 mutant was complemented (Fig. 3C). These results indicate that $F$-avi4330, a PKS gene, and its immediate downstream $F$-avi4329, an aminotransferase-encoding gene, are required for induction of tobacco HR and grape necrosis.

\section{Regulation of F-avi4330 and F-avi3342 gene expression.}

We previously reported that $\operatorname{lux} R$ homologs aviR, avhR, and $a v s R$ and an lysR-type transcriptional regulator gene, $l h n R$, in F2/5 are involved in regulation of HR and necrosis (Hao and Burr 2006; Hao et al. 2005; Zheng et al. 2003, 2012). To determine whether these genes were involved in regulation of $F$-avi4330 and $F$-avi3342, the promoter regions of $F$-avi4330 and $F$-avi3342 were amplified and cloned into the promoter-

A
A. $v$
S. f/S.m

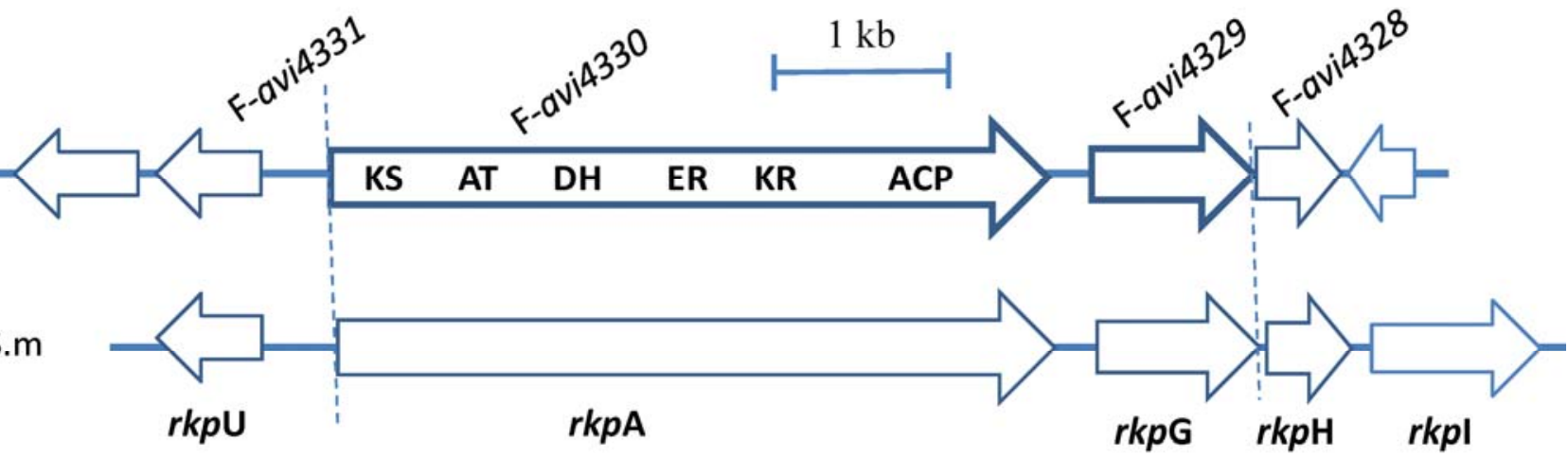

B

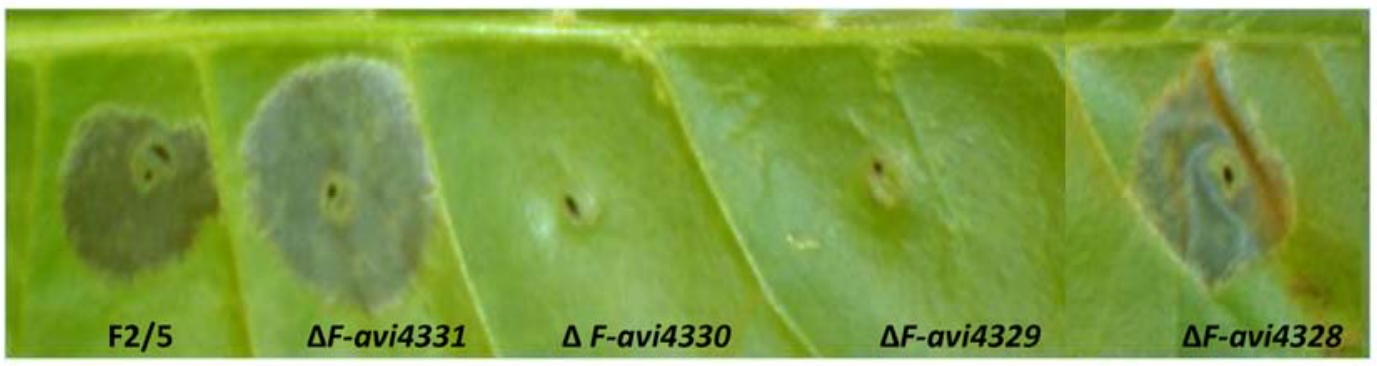

HR

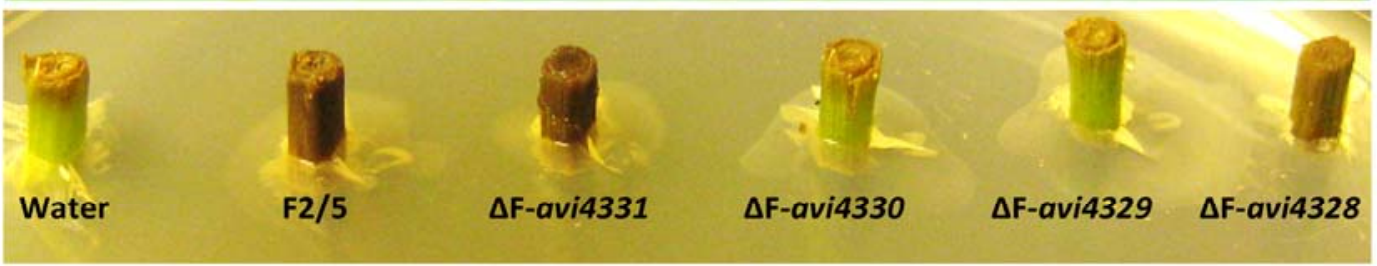

Necrosis

C

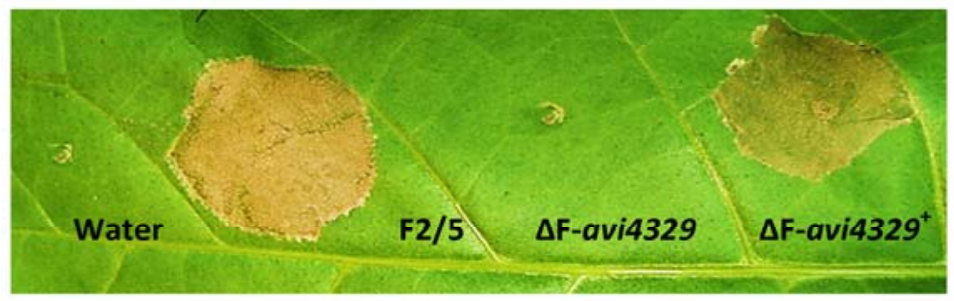

HR

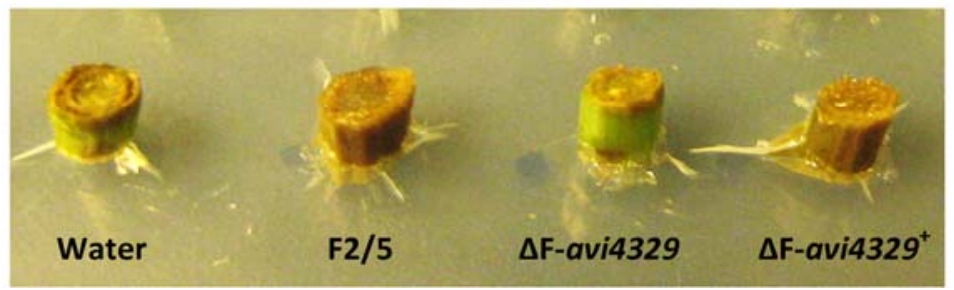

Necrosis

Fig. 3. A, Organization of F-avi4330 locus in F2/5 compared with rkp-1 loci in Sinorhizobium fredii HH103/S. meliloti 1021 (S.f./S.m.). B, Tobacco hypersensitive response (HR) and necrosis of grape shoot explants caused by $\mathrm{F} 2 / 5$ and mutants $\Delta F$-avi4331, $\Delta F$-avi4330, $\Delta F$-avi4329, and $\Delta F$-avi4328. $\mathbf{C}$, Tobacco HR and necrosis of grape shoot explants caused by F2/5, mutant $\Delta F$-avi4329, and complemented mutant $\Delta F$-avi4329+. 
probe vector, pPROBE-AT (pAT) (Miller et al. 2000) to create $F$-avi3342 promoter-green fluorescent protein $(g f p)$ fusion (pATP3342-gfp) and F-avi4330 promoter- $g f p$ fusion (pAT-P4330$g f p$ ) constructs (Fig. 4). The constructs were individually transformed into $\mathrm{F} 2 / 5$ and into the aviR, avhR, avsR, and $l h n R$ mutants. Fluorescence levels for the $a v h R$ mutant carrying pATP3342-gfp or pAT-P4330-gfp were approximately 25 and 9\% less, respectively, than those expressed in F2/5. Levels in the aviR mutant were approximately 1,120\% (11.2-fold) and 530\% (5.3-fold) less than those in F2/5 (Fig. 4). Interestingly, the fluorescence level in the $l h n R$ mutant carrying pAT-P3342-gfp was $160 \%$ (1.6-fold) greater than that in $\mathrm{F} 2 / 5$, in contrast to the avsR mutant, where fluorescence was only $15 \%$ that of F2/5 (Fig. 4). Conversely, fluorescence in the $l h n R$ mutant harboring pAT$\mathrm{P} 4330-g f p$ was $38 \%$ of that in $\mathrm{F} 2 / 5$ whereas, in the $a v s R$ mutant, the value was $150 \%$ (1.5-fold) greater than F2/5 (Fig. 4). The differences of $g f p$ expression between mutants and F2/5 reflect that $a v h R$ and aviR upregulate $F$-avi3342 and $F$-avi4330, with the regulation activity of $a v i R$ being much stronger than that of $a v h R$. It also indicates that $l h n R$ downregulates expression of $F$ avi3342 and upregulates $F$-avi4330 whereas avs $R$ upregulates $F$-avi3342 and downregulates $F$-avi4330.

Sequence analyses of $F$-avi3342 and $F$-avi4330 promoter regions identified putative recognition binding sites (RBS) characteristic of genes regulated by lys $R$-type transcriptional regulators (LTTR). The RBS in the promoter region of $F$ - avi3342 has a partial dyad symmetry, ATTGT-N ${ }_{11}$-ACAAT, containing a T- $\mathrm{N}_{11}$-A motif. It is located at position -180 from the start codon ATG, and a repeat of the upstream arm of the dyad symmetry and two such repeats occur downstream of the RBS (Fig. 5A). The putative RBS in the promoter region of $F$ avi4330 has a partial dyad symmetry, TCTGA-N7-TCAGA, containing a $\mathrm{T}-\mathrm{N}_{11}$-A motif present at -32 from the start codon ATG, and a repeat of the upstream arm of the dyad symmetry is found upstream of the RBS (Fig.5B).

To further evaluate regulation of $F$-avi3342 and $F$-avi4330 by $l h n R$, the promoter-gfp fusion constructs, pAT-P3342-gfp and pAT-P4330-gfp, were individually introduced into Escherichia coli with or without plhnR and, subsequently, gfp expression was measured. The results were consistent with those obtained in F2/5 and F2/5 mutants (Fig. 5C), confirming that $l h n R$ downregulates expression of $F$-avi3342 and upregulates F-avi4330.

Effects of killed Agrobacterium vitis cell suspensions and culture supernatants on tobacco HR and grape necrosis.

When F2/5 cell suspensions were incubated at $65^{\circ} \mathrm{C}$ for 15 min, incubated with kanamycin $(50 \mu \mathrm{g} / \mathrm{ml})$ or carbenicillin $(100 \mu \mathrm{g} / \mathrm{ml})$ at $28^{\circ} \mathrm{C}$ for $1 \mathrm{~h}$, or centrifuged to remove the cells, the treated cells and culture supernatants were not able to cause HR and necrosis (Table 1). Although cell-free F2/5 supernatant did not cause tobacco HR, when F2/5 cells were suspended in
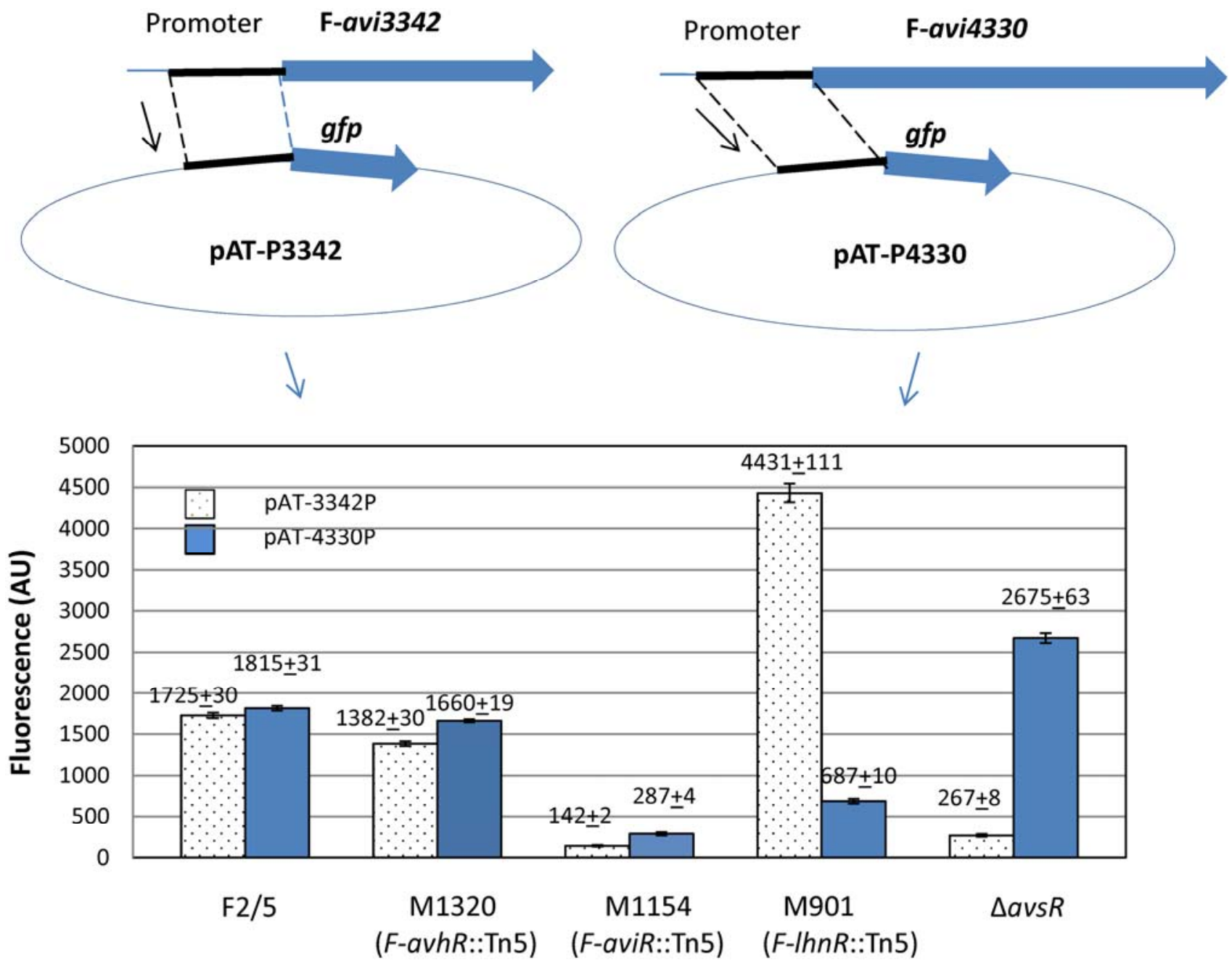

Fig. 4. Descriptions of constructs of $F$-avi3342 and $F$-avi4330 promoter-green fluorescent protein (gfp) fusion. Fluorescence measurements of Agrobacterium vitis F2/5, avhR mutant (M1320), aviR mutant (M1154), lhnR mutant (M901), and avsR mutant ( $\Delta a v s R$ ) carrying pAT-P3342-gfp or pATP4330- $g f p$, respectively. 
F2/5 cell-free supernatant, fewer cells were required to cause HR than when suspended in water (Table 2). In contrast, cellfree supernatants of $F$-avi3342, F-avi4330, F-avi4329, and $F$-avi5813 did not affect the numbers of $\mathrm{F} 2 / 5$ cells required to cause HR, and F2/5 culture supernatant was not able to complement the mutants for tobacco HR (Table 2). These results suggest that a secreted compound in supernatant is associated with the ability of F2/5 to cause the HR.

\section{DISCUSSION}

We previously reported three quorum-sensing-associated, luxR homologs and an LTTR member, $l h n R$, and its immediate upstream operon that were involved in regulation of grape necrosis and tobacco HR (Hao and Burr 2006; Hao et al. 2005; Zheng et al. 2003, 2012). In this study, we identified $F$-avi5813, an Sfp-type PPTase-encoding gene in F2/5 that is required for induction of tobacco HR and grape necrosis. Sfp-type PPTases are known to function in secondary metabolism through modification of NRPS and PKS (Lambalot et al. 1996; Walsh et al. 1997). Therefore, screening and characterization of NRPS and PKS genes present in chromosomes of $A$. vitis were performed and have led to identification of an NRPS (F-avi3342) and a $P K S$ ( $F$-4330) that are essential for tobacco HR and grape necrosis. Disruption of either $F$-avi3342 or $F$-avi4330 resulted in HR- and necrosis-negative phenotypes. This suggests that both $F$-avi3342 and $F$-avi4330 act on a pathway for biosynthesis of a compound responsible for HR and necrosis. Based on the

\begin{abstract}
A
tacgggttattgcaagtcggacactttacaaacgtgccgtgtgctgttttcattgtctcacgttt tcaggcttgtgtgcctgatttgtatatagtttgtgaattttatagcaaaatctgtgttctttta T $\quad-11 \mathrm{~N}-\quad \mathrm{A} \quad-180$

ttcgtgattgtatcgttttgcgacaatttggttttattgctttgtatttattctaatttgtgttg agcagttgaattcatgacatgctgatgtgctttatttgagtggcagttagtattttgcgtttcc tagcatcgtaatcgtttgattgtgcttgcttttgattgtttctggttttggccgatatttcag tgaggttttcaATG $\rightarrow F-$ avi 3342
\end{abstract}

B

gattagatttgcaagcgcagaccgggggtttgcgctgtcacgaatcgtatcgtcctgttgggaa tgtttgttcaggtgggtgttgataccgacattgcaatttggcgggttcctttcaaaggtctaaa accgccatccgttttgtcaagaaacgacgaaatcgtccatgaggacaaaggcacgaaccgtatc ggataacctgctcattttaagaggaaattcgaaacgggcatgttggttttcgctctcatatccg gcaggatagaagtggtttgcggggcgggtttctctctggctgccacgtctcatcaggttaaaaa atcgttctacgccataagtttccggcggtttcttcatgaggcggaggcctgcctatgtgaat cctgattgacgcccctatgtcgcttctctaagtgaaggacaattatatctgaggaca $\begin{array}{llll}\mathrm{T} & -11 \mathrm{~N}-\quad \text { A } & -32\end{array}$ tctgaaaggctatcagacctcgctaaactgttgagatccgtacgaatagATG $\rightarrow$ F-avi4330
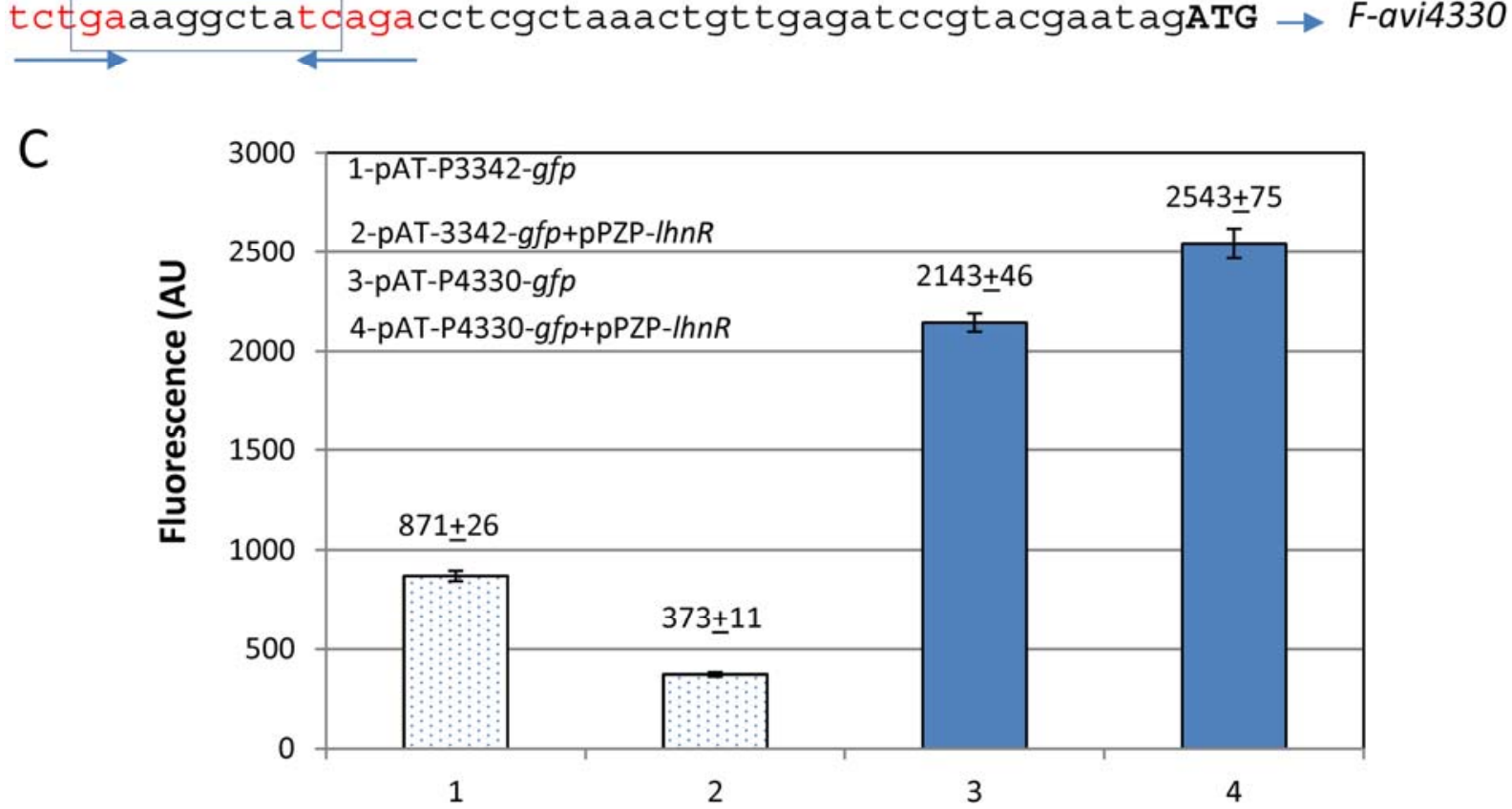

Fig. 5. DNA sequences of A, F-avi3342 and B, F-avi4330 promoter regions. The putative recognition binding site is boxed and T-N $11^{-A}$ motif is shown above the box. Two arms of a dyad symmetry element and repeats of the upstream arm of the dyad are indicated with horizontal arrows. C, Fluorescence measurement of Escherichia coli carrying F-avi3342 or F-avi4330 promoter-gfp fusion construct with or without pPZP-lhnR (plhnR). 
nature of bacterial PKS and NRPS, the compound synthesized by $F$-avi3342 and F-avi4330 is likely to be a hybrid polyketide-peptide metabolite. Biosynthesis of hybrid polyketidepeptide metabolites occurs in different ways. Most hybrid polykete-peptide metabolites examined thus far are assembled by hybrid NRPS-PKS systems that mediate direct transfer of an NRPS-bound peptidyl intermediate to a PKS module or vice versa (Du et al. 2001). Some such metabolites are synthesized by systems not involving direct functional hybridization between NRPS and PKS. For example, cyclosporin in Polycladium niveum is synthesized by, first, conversion of a poly-

Table 1. Effects of F2/5 cell suspension treatments on hypersensitive response (HR) and necrosis ${ }^{\mathrm{a}}$

\begin{tabular}{lcc}
\hline Treatment $^{\mathbf{b}}$ & $\begin{array}{c}\text { Tobacco } \\
\text { HR }\end{array}$ & $\begin{array}{c}\text { Grape } \\
\text { necrosis }\end{array}$ \\
\hline F2/5 & + & + \\
F2 $/ 5$ centrifuged and filtered $(0.25-\mu \mathrm{m}$ filter $)$ & - & - \\
$\mathrm{F} 2 / 5$ heated at $65^{\circ} \mathrm{C}$ for $15 \mathrm{~min}$ & - & - \\
$\mathrm{F} 2 / 5+\mathrm{Km}_{50}$ at $28^{\circ} \mathrm{C}$ for $1 \mathrm{~h}$ & - & - \\
$\mathrm{F} 2 / 5+\mathrm{Cb}_{100}$ at $28^{\circ} \mathrm{C}$ for $1 \mathrm{~h}$ & - & - \\
\hline
\end{tabular}

${ }^{\text {a }}$ Symbols + and - indicate positive and negative, respectively.

${ }^{\mathrm{b}} \mathrm{F} 2 / 5$ cell suspension, optical density at $600 \mathrm{~nm}=2.0, \mathrm{Km}_{50}=$ kanamycin $(50 \mu \mathrm{g} / \mathrm{ml})$, and $\mathrm{Cb}_{100}=$ carbenicillin $(100 \mu \mathrm{g} / \mathrm{ml})$. ketide intermediate into amino acid and, subsequently, incorporation of this amino acid into the natural product by an NRPS (Offenzeller et al. 1996; Weber et al. 1994). In A. vitis, biosynthesis of the putative hybrid polyketide-peptide product

Table 2. Effect of supernatants of F2/5 and its mutants on tobacco hypersensitive response (HR) caused by Agrobacterium vitis ${ }^{\mathrm{a}}$

\begin{tabular}{lccc}
\hline Treatment & $\begin{array}{c}\text { Cell density } \\
\left(\mathbf{O D}_{\mathbf{6 0 0}}\right)\end{array}$ & $\begin{array}{c}\text { No of } \\
\text { inoculations }\end{array}$ & $\begin{array}{c}\text { No. of } \\
\text { HR positive }\end{array}$ \\
\hline F2/5 suspended in & & & \\
$\quad$ Supernatant of $\mathrm{F} 2 / 5$ & 0.5 & 10 & 8 \\
$\quad$ Supernatant of $\Delta F$-avi5813 & 0.5 & 10 & 0 \\
$\quad$ Supernatant of $\Delta F$-avi3342 & 0.5 & 10 & 0 \\
$\quad$ Supernatant of $\Delta F$-avi4330 & 0.5 & 10 & 0 \\
Supernatant of $\Delta F$-avi4329 & 0.5 & 10 & 0 \\
$\quad$ Water & 2.0 & 10 & 10 \\
Supernatant of F2/5 alone & 0 & 10 & 0 \\
Suspended in F2/5 & & & \\
$\quad \Delta F$-avi5813 & 2.0 & 10 & 0 \\
$\Delta F$-avi3342 & 2.0 & 10 & 0 \\
$\Delta F$-avi4330 & 2.0 & 10 & 0 \\
$\Delta F$-avi4329 & 2.0 & 10 & 0 \\
\hline
\end{tabular}

${ }^{a}$ The supernatant was prepared by centrifuging the cell suspension (optical density at $600 \mathrm{~nm}\left[\mathrm{OD}_{600}\right]=2.0$ ) and filtering through a 0.25 $\mu \mathrm{m}$ filter.

b Mutants suspended in supernatant of F2/5.

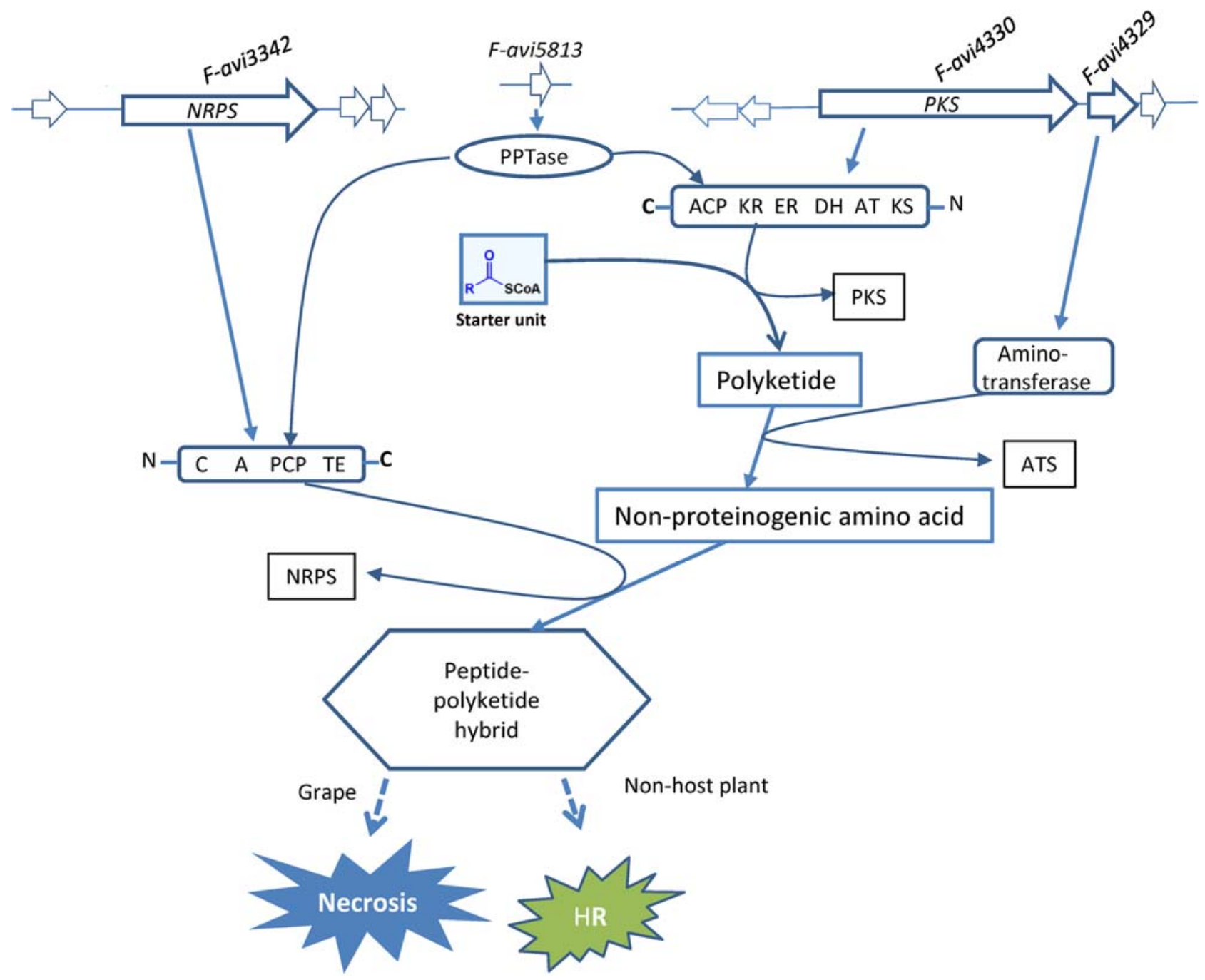

Fig. 6. Predicted biosynthetic pathway for a putative hybrid polyketide-peptide metabolite in Agrobacterium vitis. Domains polyketide synthase (PKS) and nonribosomal peptide synthase (NRPS) are listed and boxed. $\mathrm{N}$ terminus and $\mathrm{C}$ terminus of PKS and NRPS protein are marked with $\mathrm{N}$ and $\mathrm{C}$ outside the boxes. ATS refers to aminotransferase. 
may be similar to cyclosporin. We predict that the polyketide intermediate is first synthesized from a starter unit by catalysis of the F-avi4330-encoded PKS and then converted into an amino acid by the $F$-avi4329-encoded aminotransferase (Fig. $6)$. The specific amino acid is subsequently incorporated into the product by the $F$-avi3342-encoded NRPS. The ACP in PKS (F-avi4330) and PCP in NRPS (F-avi3342) are activated by PPTase F-avi5813 (Fig. 6). Verification of the hybrid polyketide-peptide compound synthesized by $F$-avi3342 and $F$-avi4330 remains to be determined by biochemical analysis, and whether there are genes encoding tailoring enzymes involv- ing this compound biosynthesis also remain to be determined. A homolog of $F$-avi3342 occurs in A. radiobacter $\mathrm{K} 84$ and the locus of $F$-avi4330 exists within the $r k p$ - 1 region of Sinorhizobium spp., which is required for production of capsular polysaccharide in S. fredii $\mathrm{HH} 103$ and S. meliloti 1021 (Hidalgo et al. 2010; Müller et al. 2009, Parada et al. 2006). However, homologs of $F$-avi3342 and F-avi4330 together in the same genome have not been reported for other Rhizobiaceae spp. Production of such a hybrid PK-NRP molecule may explain why $A$. vitis has the unique ability among Rhizobiaceae spp. investigated thus far to cause HR and grape necrosis.

Table 3. Bacterial strains and plasmids used in this study

\begin{tabular}{|c|c|c|}
\hline Bacterial strains & Relevant characteristics $^{\mathbf{a}}$ & Reference \\
\hline \multicolumn{3}{|l|}{ Agrobacterium vitis } \\
\hline $\mathrm{F} 2 / 5$ & Wild type & Staphorst et al. 1985 \\
\hline M1154 & $\mathrm{F} 2 / 5$ aviR $: \mathrm{Tn} 5, \mathrm{Km}^{\mathrm{r}}$ & Zheng et al. 2003 \\
\hline M1320 & $\mathrm{F} 2 / 5$ avhR::Tn5, $\mathrm{Km}^{\mathrm{r}}$ & Hao et al. 2005 \\
\hline M901 & $\mathrm{F} 2 / 5 \operatorname{lhn} R: \mathrm{Tn} 5, \mathrm{Km}^{\mathrm{r}}$ & Harlache et al. 2001 \\
\hline$\Delta a v s R$ & $\mathrm{~F} 2 / 5$ avsR $:: \mathrm{pPVIK} 165, \mathrm{Km}^{\mathrm{r}}$ & Hao and Burr 2006 \\
\hline$\Delta F$-avi5813 & F-avi5813::pPVIK165, $\mathrm{Km}^{\mathrm{r}}$ & This work \\
\hline$\Delta F$-avi $5813^{+}$ & $\Delta F$-avi5813 carrying pPZP-5813, $\mathrm{Km}^{\mathrm{r}}, \mathrm{Sp}^{\mathrm{r}}$ & This work \\
\hline$\Delta F$-avi3342 & F-avi3342::pPVIK165, $\mathrm{Km}^{\mathrm{r}}$ & This work \\
\hline$\Delta F$-avi4330 & F-avi4330::pPVIK165, $\mathrm{Km}^{\mathrm{r}}$ & This work \\
\hline$\Delta F$-avi4329 & F-avi4329::pPVIK165, $\mathrm{Km}^{\mathrm{r}}$ & This work \\
\hline$\Delta F$-avi4329+ & $\Delta F$-avi4329 carrying pWSK-4329, $\mathrm{Km}^{\mathrm{r}}, \mathrm{Sp}^{\mathrm{r}}$ & This work \\
\hline$\Delta F$-avi5730 & F-avi5730::pPVIK165, $\mathrm{Km}^{\mathrm{r}}$ & This work \\
\hline \multicolumn{3}{|l|}{ Escherichia coli } \\
\hline DH5 $\alpha$ & See source & Invitrogen \\
\hline JM109 & See source & Promega Corp. \\
\hline S17-1/入 pir & RK2 tra regulon, pir, host for pir-dependent plasmids & Simon et al. 1983 \\
\hline \multicolumn{3}{|c|}{ 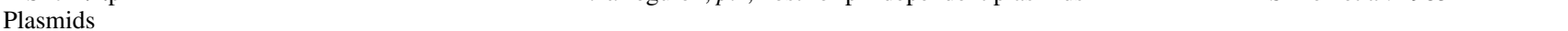 } \\
\hline pPROBE-AT & Broad host range vector, $\mathrm{Cb}^{\mathrm{r}}$ & Miller et al. 2000 \\
\hline pPZP201 & Broad-host range cloning vector, $\mathrm{Sp}^{\mathrm{r}}$ & Hajdukiewicz et al. 1994 \\
\hline $\mathrm{p} l h n R$ & pPZP201 carrying $l h n R, \mathrm{Sp}^{\mathrm{r}}$ & Zheng et al. 2012 \\
\hline pVIK165 & Suicide-vector, $\mathrm{Km}^{\mathrm{r}}$ & Kalogeraki and Winans 1997 \\
\hline pWSK29 & Low-copy-number vector, $\mathrm{Cb}^{\mathrm{r}}$ & Wang and Kushner 1991 \\
\hline pPZP-5813 & pPZP201 carrying avi5813, $\mathrm{Sp}^{\mathrm{r}}$ & This work \\
\hline pWSK-4329 & pWSK-29 carrying $F$-avi4329, $\mathrm{Cb}^{\mathrm{r}}$ & This work \\
\hline pAT-P3342 & pPROBE-AT carrying $F$-avi3342 promoter, $\mathrm{Cb}^{\mathrm{r}}$ & This work \\
\hline pAT-P4330 & pPROBE-AT carrying F-avi4330 promoter, $\mathrm{Cb}^{\mathrm{r}}$ & This work \\
\hline
\end{tabular}

${ }^{a} \mathrm{Km}^{\mathrm{r}}, \mathrm{Sp}^{\mathrm{r}}$, and $\mathrm{Cb}^{\mathrm{r}}$ indicate kanamycin, spectinomycin, and carbenicillin resistance, respectively.

Table 4. Primers used in this study

\begin{tabular}{|c|c|c|}
\hline Gene & Primer & Primer sequence $^{\mathrm{a}}$ \\
\hline \multicolumn{3}{|c|}{ For mutagenesis } \\
\hline \multirow[t]{2}{*}{ F-avi3342 } & F-avi3342-F: & 5'-ATGAGCTCTCTGGTATCATTGGGCACATC-3' \\
\hline & F-avi3342-R: & $5^{\prime}$-AGTCTAGAGAATGTCCTCATAGCGATAGC-3' \\
\hline \multirow[t]{2}{*}{ F-avi4328 } & F-avi4328-F: & $5^{\prime}$-ACGAGCTCCTCGCTTGTGCGTGTTGAGAC-3' \\
\hline & F-avi4328-R: & $5^{\prime}$-AGTCTAGATGACATTGATGTCGAGTTGCTG-3' \\
\hline \multirow[t]{2}{*}{ F-avi4329 } & F-avi4329-F: & 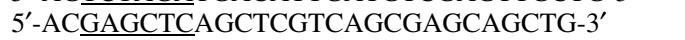 \\
\hline & F-avi4329-R: & $5^{\prime}$-AGTCTAGATGAACTCGTCATGGATCACCAG-3' \\
\hline \multirow[t]{2}{*}{ F-avi4330 } & F-avi4330-F: & 5'-ATGAGCTCTGTGATGGATGGAATCTATCAG-3' \\
\hline & F-avi4330-R: & 5'-AGTCTAGATCATAGACGGCATGCAGCAGAAC-3' \\
\hline \multirow[t]{2}{*}{ F-avi4331 } & F-avi4331-F: & $5^{\prime}$-ACGAGCTCGTCTGATGATCCTCGTTCTG-3' \\
\hline & F-avi4331-R: & $5^{\prime}$-AGTCTAGAATCTGTCTTTCTGTCTCGAC-3' \\
\hline \multirow[t]{2}{*}{ F-avi5730 } & F-avi5730-F: & $5^{\prime}$-ATGAGCTCTTGCTTGATGCAGCACATTTG-3' \\
\hline & F-avi5730-R: & 5'-AGTCTAGATCGATCATTGCATCACTATGG-3' \\
\hline \multirow[t]{2}{*}{ F-avi5813 } & F-avi5813-F: & 5'-AA $\overline{\text { GAATTCTTGATCTCGCATCGCGCTG-3' }}$ \\
\hline & F-avi5813-R: & 5'-AATCTAGATGCGCTGTCATGACCTGTTCTG-3' \\
\hline Vector & pVIK165-R: & 5'-TACTCATCTTTGTTTCCTCC-3' \\
\hline \multicolumn{3}{|c|}{ For complementation } \\
\hline \multirow[t]{2}{*}{ F-avi4329 } & F-avi4329-FF: & 5'-AGAAGCTTTGGTTCTTGCTATCCGTTACAC-3' \\
\hline & F-avi4329-RR: & 5'-ACGAGCTCAGTTCAGGTGCTCAAGGACGAG-3' \\
\hline \multirow[t]{2}{*}{ F-avi5813 } & F-avi5813-FF: & $5^{\prime}$-ACAAGCTTGGTTCTTGCTATCCGTTACAC- $3^{\prime}$ \\
\hline & F-avi5813-RR: & $5^{\prime}$-AAGAATTCGCTAAATTATAACGCAGCCTCATC- ${ }^{\prime}$ \\
\hline \multicolumn{3}{|c|}{ For promoter- $g f p$ fusion } \\
\hline F-avi3342 & P3342-F: & 5'-ACGAGCTCACGGGTTATTGCAAGTCGGTC-3' \\
\hline \multirow[t]{2}{*}{ F-avi4330 } & P4330-F: & $5^{\prime}$-AGAAGCTTGATTAGATTTGCAAGCGCAGAC- $3^{\prime}$ \\
\hline & P4330-R: & $5^{\prime}$-ATGAGCTCGATCTCAACAGTTTAGCGAG- $3^{\prime}$ \\
\hline
\end{tabular}

\footnotetext{
${ }^{a}$ Restriction sites are underlined.
} 
Promoter- $g f p$ fusions were used to determine that expression of $F$-avi3342 and $F$-avi4330 are regulated by avhR, aviR, avsR, and $l h n R$ in different ways (Fig. 4). Both $a v h R$ and $a v i R$ upregulate expression of $F$-avi3342 and $F$-avi4330 whereas $\operatorname{lhn} R$ downregulates $F$-avi3342 and upregulates $F$-4330. In contrast to $l h n R$, avsR upregulates $F$-avi3342 but downregulates $F-4330$ (Fig. 4). These results indicate that the expression levels of $F$-avi3342 and $F$-avi4330 affect tobacco HR and grape necrosis and transcriptional regulators $a v h R$, aviR, avsR, and $l h n R$ play essential roles in regulation of $F$-avi3342 or $F$-avi4330. The results also suggest that expression levels of $F$-avi3342 and $F$-avi4330 may be correlated with the production of the putative hybrid polyketide-peptide metabolite and subsequent induction of HR and necrosis. In other bacteria, it has also been shown that LuxR and LysR-type transcriptional factors regulate polyketide or nonribosomal peptide biosynthesis. For example, production of enacyloxins, the antimicrobial compounds synthesized by a hybrid modular PKS gene cluster in cryptic Burkholderia ambifaria, are positively regulated by two LuxR-type regulators (Mahenthiralingam et al. 2011). In addition, SylA, a member of the LuxR family, positively regulates biosynthesis of syringolin A, a phytotoxin synthesized by a mixed nonribosomal peptide/polyketide synthetase in Pseudomonas syringae pv. syringae (Ramel et al. 2012); and the pltR, a putative LysR-type regulator, positively regulates biosynthesis of pyoluteorin, an antifungi polyketide, in Pseudomonas sp. M18 (Yan et al. 2007). An RBS of LTTR exists in the promoter region of $F$-avi3342 at $-180 \mathrm{bp}$ from the start codon and another RBS in the promoter region of $F$-avi4330 at -32 bp from its start codon (Fig. 5A and B). Co-transformation of promoter- $g f p$ fusion constructs and $l h n R$ into $E$. coli confirmed that $l h n R$ suppresses $F$-avi3342 and enhances $F$-avi4330 expression (Fig. 5C). These results suggest that $l h n R$ directly targets promoters of $F$-avi3342 and $F$-avi4330 by binding to their RBS and that regulation by LhnR may depend on the location of an RBS in the promoter of the target gene. No motifs indicative of lux boxes were found in the $F$ avi3342 and $F$-avi4330 promoters; therefore, how avhR, aviR, and $a v s R$ proteins interact with $F$-avi3342 and $F$-avi4330 remains to be determined.

We now predict that a putative polyketide-peptide hybrid compound is produced by $A$. vitis and appears to be acting as a phytotoxin associated with grape (host) necrosis and induction of tobacco (nonhost) HR. Living cells of A. vitis are essential for induction of tobacco HR and grape necrosis whereas cells killed using various methods and culture supernatants were unable to do so (Table 1). Promoter- $g f p$ fusion analyses and reverse-transcription PCR (results not shown) indicated that the related biosynthetic genes were transcribed under in vitro conditions even though we obtained no direct evidence that a specific elicitor molecule was secreted in culture media. This scenario is similar to colibactin, a genotoxin produced by certain strains of $E$. coli. Colibactin is a polyketide-peptide hybrid compound that causes double-strand DNA breaks (Nougayrède et al. 2006). The genes responsible for colibactin biosynthesis were discovered in the pks island and were transcribed under in vitro conditions. The cytopathic activity of colibactin is contact dependent and the killed bacteria, bacterial culture supernatants, and bacterial lysates were not cytopathic (Nougayrède et al. 2006). In our experiments, it was found that bacterial cultural supernatant enhances biological activity of F2/5 (i.e., fewer cells are required to induce HR when suspended in the supernatant) (Table 2). This may indicate that a level of the putative hybrid polyketide-peptide compound is produced in vitro but is too low to induce the plant response. It may also suggest that the production of the specific elicitor molecule is enhanced by stimuli of plant signal molecules when A. vitis is in contact with plant cells.
It has been reported that production of some phytotoxins requires plant signal molecules. For example, synthesis of the phytotoxin syringomycin by $P$. syringae pv. syringae required plant signal molecules arbutin and D-fructose for activation of biosynthetic gene syrB (Mo et al. 1995; Qingley and Gross 1994; Wang et al. 2006). Further research is needed to determine whether plant signals are involved in production of the putative hybrid polyketide-peptide by $A$. vitis.

\section{MATERIALS AND METHODS}

\section{Bacterial stains, media, and plasmids.}

Bacterial strains used in this study are listed in Table 3. A. vitis strain $\mathrm{F} 2 / 5$ is nontumorigenic and was used previously in our laboratory to study HR and grape necrosis (Herlache et al. 2001). F2/5 was propagated on potato dextrose agar (PDA) or in potato dextrose broth (Difco Laboratories, Detroit) at $28^{\circ} \mathrm{C}$. Appropriate antibiotics were added to the media for culturing mutants. E. coli were cultured on Luria-Bertani (LB) medium with appropriate antibiotics at $37^{\circ} \mathrm{C}$.

\section{Sequence analyses.}

Genes targeted for mutation and DNA fragments amplified from F2/5 were cloned into vector pGEM-T and were sequenced at The Cornell University Life Sciences Core Laboratories Center. Genes in F2/5 that correspond to those in S4 were designated as $\mathrm{F}$ followed by the gene ID number of S4. DNA sequence homologies were evaluated with the Basic Local Alignment Search Tool algorithm provided by the National Center for Biotechnology Information. Analyses of DNA and deduced protein sequences were carried out with DNASTAR software.

\section{Mutagenesis by targeted gene disruption.}

Specific mutants were generated through disruption with suicide vector pVIK165 (Kalogeraki and Winans 1997). Internal fragments of target genes were amplified from F2/5 genomic DNA via PCR employing primers listed in Table 4. Restriction sites were introduced into forward and reverse primers. PCR products were purified, digested, and then ligated into suicide vector pVIK165 (Kalogeraki and Winans 1997) at corresponding restriction sites. The constructs were transformed into $E$. coli strain S17-1/ $\lambda$ pir and selected on LB agar plus kanamycin $(50 \mu \mathrm{g} / \mathrm{ml})$. Constructs were transferred to F2/5 via conjugal mating, and targeted gene disruptions by insertion of vector pVIK165 sequence occurred following a single homologous recombination. The resulting mutants contained two truncated copies of the target gene separated by the inserted plasmid. Mutants were selected on $\mathrm{AB}$ minimal medium (Chilton et al. 1974) amended with kanamycin $(50 \mu \mathrm{g} / \mathrm{ml})$ and $10 \%$ mannitol. Mutations were verified by PCR using primers derived from sequences of the F2/5 and from the pVIK165 vector (Table 4). Mutants were tested for their ability to cause the tobacco HR and grape necrosis.

\section{Complementation of mutants.}

Complementation of the $\Delta F$-avi5813 and $\Delta F$-avi4329 mutants were performed using methods previously described (Hao et al. 2005). Full-length targeted sequences including their promoter regions were amplified from F2/5 genomic DNA; the PCR product of $F$-avi5813 was cloned into a broad-host-range vector, pPZP201 (Hajdukiewicz et al. 1994), and PCR product of $F$-avi4329 was cloned into a lowcopy-number vector, pWSK29 (Wang and Kushner 1991). The plasmid constructs were transformed into DH5 $\alpha$-competent cells. Positive colonies were selected on LB agar containing spectinomycin $(100 \mu \mathrm{g} / \mathrm{ml})$. The recombinant plasmids 
that were designated as pPZP-5813 and pWSK-4329 were verified by restriction analyses and sequencing. The pPZP5813 and pWSK-4329 were conjugated into $\Delta F$-avi5813 and $\Delta F$-avi4329, respectively, by conjugation. Transconjugants were selected on $\mathrm{AB}$ (plus $10 \%$ mannitol) minimal medium containing spectinomycin $(400 \mu \mathrm{g} / \mathrm{ml})$ and kanamycin $(100$ $\mu \mathrm{g} / \mathrm{ml}$ ) and verified by PCR. Expression of the recombined $F$-avi5813 and F-avi4329 in the complementation constructs are driven by their native promoters. Complemented $\Delta F$ avi5813 and $\Delta F$-avi4329 were tested for their ability to cause tobacco HR and grape necrosis.

\section{Construction and assay \\ of $F$-avi3342 and $F$-avi4330 promoter- $g f p$ fusions.}

As indicated previously, three quorum-sensing regulatory genes and an lysR-type regulatory gene were shown to be associated with HR and necrosis. To determine whether expression of $F$-avi3342 and $F$-avi4330 was regulated by these genes, promoter-gfp fusions were initially constructed. The promoter regions of $F$-avi3342 (337 bp) and $F$-avi4430 (479 bp) were amplified from F2/5 genomic DNA and cloned into the promoter probe vector, pPROBE-AT (Miller et al. 2000), to create $F$-avi3342 promoter-gfp fusion (pAT-P3342-gfp) and $F$-avi4330 promoter-gfp fusion (pAT-P4330-gfp). Both of the resulting constructs are transcriptional fusions. The constructs were introduced into F2/5 and mutants M1320 (Tn5 mutant of $a v h R$ ), M1154 (Tn5 mutant of aviR), M901 (Tn5 mutant of $l h n R$ ), and $\Delta a v s R$. The promoter-gfp fusion constructs were also introduced into $E$. coli strain JM109 with or without co-transformation with plhnR (Table 3) to further elucidate regulation of $F$-avi3342 and $F$-avi4330 by lhnR. A. vitis strains were grown on PDA amended with kanamycin $(50 \mu \mathrm{g} / \mathrm{ml})$ and carbenicillin $(100 \mu \mathrm{g} / \mathrm{ml})$ at $28^{\circ} \mathrm{C}$ for 3 days and $E$. coli on LB agar with kanamycin $(50 \mu \mathrm{g} / \mathrm{ml})$ and carbenicillin $(100 \mu \mathrm{g} / \mathrm{ml})$ at $37^{\circ} \mathrm{C}$ overnight. Subsequently, bacterial cells containing promoter- $g f p$ fusion constructs were suspended in water and cell concentrations were adjusted to an optical density at $600 \mathrm{~nm}\left(\mathrm{OD}_{600}\right)$ of 0.5 (approximately $5 \times$ $10^{8} \mathrm{CFU} / \mathrm{ml}$ ). Then, $200 \mu \mathrm{l}$ of the cell suspensions were transferred to black 96-well Cliniplates (Labsystems, Franklin, MA, U.S.A) and fluorescence assays were performed using a Multi-mode Microplate reader Synergy 2 (Biotek Instruments Inc., Winooski, VT, U.S.A.). Fluorescence was measured with an FITC filter set (excitation of $485 \pm 20$ and emission of $508 \pm 20$ ) with a sensitivity of 55 on a scale of 100. Fluorescence data were analyzed using the Gene5 Data Analysis Software (v1.06; Biotek Instruments Inc.). Fluorescence readings of $\mathrm{F} 2 / 5$ or JM109 with empty vector pPROBE-AT were set as background. The avsR mutant was generated employing suicide vector pVIK165, which also contains a $g f p$. Therefore, to determine $g f p$ expression driven by the $F$-avi3342 or $F$-avi4430 promoter in $\Delta a v s R$, fluorescence of $\Delta a v s R$ not carrying the promoter- $g f p$ fusion constructs was measured as background. Readings were subtracted from background and at least three independent experiments were done with 12 replicates each that were averaged.

\section{Tobacco HR and grape necrosis assay.}

HR was determined by infiltration of tobacco leaves with A. vitis cell suspensions, as previously described (Herlache et al. 2001). Necrosis assays were done on young grape shoot explants (Herlache et al. 2001). Shoots were cut into 0.5-cm sections and supported on end in water agar (2\%) with basal end up. Cell suspensions $(5 \mu \mathrm{l})$ of F2/5 and F2/5 mutants were placed on the basal end of each explant and necrosis was observed 5 to 7 days after inoculation.
Effects of killed $A$. vitis cell suspensions and culture supernatants on tobacco $H R$ and grape necrosis.

F2/5 was grown on PDA plates at $28^{\circ} \mathrm{C}$ for 2 days and then cells were suspended in water by vortexing. Cell densities were adjusted at $\mathrm{OD}_{600}$ to 2.0 and suspensions were either i) heated at $65^{\circ} \mathrm{C}$ for $15 \mathrm{~min}$, ii) treated with kanamycin $(50$ $\mu \mathrm{g} / \mathrm{ml})$ or carbenicillin $(100 \mu \mathrm{g} / \mathrm{ml})$ at $28^{\circ} \mathrm{C}$ for $1 \mathrm{~h}$ with shaking $(200 \mathrm{rpm})$, or iii) centrifuged, and the supernatants were filtered through a $0.25-\mu \mathrm{m}$ filter. The treated suspensions were compared with an untreated suspension of F2/5 for ability to cause HR and necrosis.

In addition, the effects of mutant and F2/5 cell-free supernatants on the concentrations of F2/5 cells required to cause HR was determined. F2/5 cells grown on PDA plates were suspended in water or in the cell-free supernatants and adjusted to different ODs. The supernatant was prepared as mentioned above. The suspensions were infiltrated into tobacco leaves to determine ability to cause HR.

\section{ACKNOWLEDGMENTS}

We thank S. C. Winans (Cornell University) for vectors pVIK165 and pPZP201, S. E. Lindow (University of California-Berkeley) for vector pPROBE-AT, S. R. Kushner (University of Georgia) for vector pWSK29, and C. Reid and B. Dehaven for assistance in preparation of plant materials. This work was partially supported by the United States Department of Agriculture Federal Formula Funds proposal 2012-13-152.

\section{LITERATURE CITED}

Bender, C. L., Alarcón-Chaidez, F., and Gross, D. C. 1999. Pseudomonas syringe phytotoxins: Mode of action, regulation, and biosynthesis by peptide and polyketide synthetases. Microbiol. Mol. Biol. Rev. 63:266-292.

Birch, R. G., and Patil, S. S. 1985. June 1985. Antibiotic and process for the production thereof. U. S. patent 4,525,354.

Birch, R. G., and Patil, S. S. 1987. Evidence that an albicidin-like phytotoxin induces chlorosis in sugarcane leaf scald disease by blocking plastid DNA replication. Mol. Plant Pathol. 30:207-214.

Burr, T. J., and Otten, L. 1999. Crown gall of grape: Biology and disease management. Annu. Rev. Phytopathol. 37:53-80.

Burr, T. J., Bishop, A. L., Katz, B. H., Blanchard, L. M., and Bazzi, C. 1987. A root-specific decay of grapevine caused by Agrobacterium tumefaciens and A. radiobacter biovar 3. Phytopathology 77:1424-1427.

Büttner, D., and He, S.Y. 2009. Type III protein secretion in plant pathogenic bacteria. Plant Physiol. 150:1656-1664.

Chilton, M., Currier, T. C., Farrand, S. K., Bendich, A. J., Gordon, M. P. and Nester, E.W. 1974 Agrobacterium tumefaciens DNA and Ps8 bacteriophage DNA not detected in crown gall tumorigenesis. Proc. Natl. Acad. Sci. U.S.A. 71, 3672-2676.

Cane, D. E., and Walsh, C. T. 1999. The parallel and convergent universes of polyketide synthases and nonribosomal peptide synthetases. Chem. Biol. 6:R319-R325.

Carle, S. A., Hao, G., Zheng, D., Sanni-Sanoussi, T., Talarico, M. J., Hilton, J. S., and Burr, T. J. 2008. A gene cluster in Agrobacterium vitis homologous to polyketide synthase operons is associated with grape necrosis and hypersensitive response induction on tobacco. FEMS (Fed. Eur. Microbiol. Soc.) Microbiol. Lett. 289:90-96.

Conti, E., Stachelhaus, T., Marahiel, M. A., and Brick, P. 1997. Structural basis for the activation of phenylalanine in the non-ribosomal biosynthesis of gramicidine S. EMBO (Eur. Mol. Biol. Organ.) J. 16:41744183.

Du, L., Sanchez, C., Chen, M., Edwards, D. J., and Shen, B. 2000. The biosynthetic gene cluster for the antitumor drug bleomycinfrom Streptomyces verticillus ATCC15003 supporting functional interactions between nonribosomal peptide synthetases and a polyketide synthase. Chem. Biol. 7:623-642.

Du, L., Sanchez, C., and Shen, B. 2001. Hybrid peptide-polyketide natural products: Biosynthesis and prospects toward engineering novel molecules. Metab. Eng. 3:78-95.

Gokhale, R. S., Sankaranarayanan, R., and Mohanty, D. 2007. Versatility of polyketide synthases in generating metabolic diversity. Curr. Opin. Struct. Biol. 17:736-743.

Hajdukiewicz, P., Svab, Z., and Maliga, P. 1994. The small versatile pPZP family of Agrobacterium binary vectors for plant transformation. Plant Mol. Biol. 25:989-994. 
Hao, G., and Burr, T. J. 2006. Regulation of long-chain N-acyl-homoserine lactones in Agrobacterium vitis. J. Bacteriol. 188:2173-2183.

Hao, G., Zhang, H. S., Zheng, D. S., and Burr, T. J. 2005. luxR Homolog avhR in Agrobacterium vitis affects the development of a grape-specific necrosis and a tobacco hypersensitive response. J. Bacteriol. 187:185192.

Herlache, T. C., Zhang, H. S., Reid, C. L., Carle, S., Zheng, D., Basaran, P., Thaker, M., Burr, A. T., and Burr, T. J. 2001. Mutations that affect Agrobacterium vitis-induced grape necrosis also alter its ability to cause a hypersensitive response on tobacco. Phytopathology 91:966-972.

Hertweck, C. 2009. The biosynthetic logic of polyketide diversity. Angew. Chem. Int. Ed. 48:4688-4716.

Hidalgo, A., Margaret, I., Crespo-Rivas, J. C., Parada, M., Murdoch, P. S., López, A., Buendía-Clavería, A. M., Moreno, J., Albareda, M., GilSerrano, A. M., Rodrí́guez-Carvajal, M. A., Palacios, J. M., RuizSainz, J. E., and Vinardell, J. M. 2010. The rkpU gene of Sinorhizobium fredii $\mathrm{HH} 103$ is required for bacterial $\mathrm{K}$-antigen polysaccharide production and for efficient nodulation with soybean but not with cowpea. Microbiology 156:3398-3411.

Huang, G., Zhang, L., and Birch, R. G. 2001. A multifunctional polyketide-peptide synthetase essential for albicidin biosynthesis in Xanthomonas albilineans. Microbiology 147:631-642.

Kalogeraki, V. S., and Winans, S. C. 1997. Suicide plasmids containing promoterless reporter genes can simultaneously disrupt and create fusions to target genes of diverse bacteria. Gene 188:69-75.

Lambalot, R. H., Gehring, A. M., Flugel, R. S., Zuber, P., LaCelle, M. Marahiel, M. A., Reid, R., Khosla, C., and Walsh, C. T. 1996. A new enzyme superfamily: The phosphopantetheinyl transferases. Chem. Biol. 3:923-936.

Mahenthiralingam, E., Song, L., Sass, A., White, J., Wilmot, C., Marchbank, A., Boaisha, O., Paine, J., Knight, D., and Gregory, L., and Challis, G. L. 2011. Enacyloxins are products of an unusual hybrid modular polyketide synthase encoded by a cryptic Burkholderia ambifaria genomic island. Chem. Biol. 18:665-677.

May, J. J., Wendrich, T. M., and Marahiel, A. 2001. The $d h b$ operon of Bacillus subtilis encodes the biosynthetic template for catecholic siderophore 2,3-dihydroxybezoate-glycine-threonine trimeric easter bacilibactin.

Miller, W. G., Leveau, J. H., and Lindow, S. E. 2000. Improved gfp and inaZ broad-host-range promoter-probe vectors. Mol. Plant-Microbe Interact. 13:1243-1250.

Mo, Y. Y., Ceibel, M., Bonsall, R. F., and Cross, D. C. 1995. Analysis of sweet cherry (Prunus avium L.) leaves for plant signal molecules that activate the $\operatorname{syr} B$ gene required for synthesis of the phytotoxin, sringomycin, by Pseudomonas syringae pv. syringae. Plant Physiol. 107:603612

Müller, M. G., Forsberg, L. S., and Keating, D. H. 2009. The $r k p-1$ cluster is required for secretion of kdo homopolymeric capsular polysaccharide in Sinorhizobium meliloti strain Rm1021. J. Bacteriol. 191:6988-7000.

Nougayrède, J.-P., Stefan Homburg, S., Taieb, F., Boury, M., Brzuszkiewicz, E., Gottschalk, G., Buchrieser, C., Hacker, J., Ulrich Dobrindt, U., and Oswald, E. 2006. Escherichia coli induces DNA doublestrand breaks in eukaryotic cells. Science 313:848-851.

Offenzeller, M., Santer, G., Totschnig, K., Su, Z., Moser, H., Traber, R., and Schneider-Scherzer, E. 1996. Biosynthesis of the unusual amino acid (4R)-4-[(E)-2-butenyl]-4-methyl-1-threonine of cyclosporin A: Enzymatic analysis of the reaction sequence including identification of the methylation precursor in a polyketide pathway. Biochemistry 35:8401-8412.

Parada, M., Vinardell, J. M., Ollero, F. J., Hidalgo, A., Gutiérrez, R., Buendía-Clavería, A. M., Lei, W., Margaret, I., López-Baena, F. J., Antonio, M., Gil-Serrano, A. M., Miguel A., Rodríguez-Carvajal, M. A.,
Javier Moreno, J., and Ruiz-Sainz, J. E. 2006. Sinorhizobium fredii HH103 mutants affected in capsular polysaccharide (KPS) are impaired for nodulation with soybean and Cajanus cajan. Mol. Plant-Microbe Interact. 19:43-52.

Quigley, N. B., and Gross, D. C. 1994. Syringomycin production among strains of Pseudomonas syringae pv. syringae: Conservation of the syrB and $s y r D$ genes and activation of phytotoxin production by plant signal molecules. Mol. Plant-Microbe Interact. 7:78-90.

Ramel, C., Baechler, N., Hildbrand, M., Meyer, M., Schädeli, D., and Dudler, R. 2012. Regulation of biosynthesis of syringolin A, a Pseudomonas syringae virulence factor targeting the host proteasome. Mol. Plant-Microbe Interact. 25:41198-41208.

Royer, M., Costet, L., Vivien, E., Bes, M., Cousin, A., Damais, A., Pieretti, I., Savin, A., Megessier, S., Viard, M., Frutos, R., Gabriel, D. W., and Rott, P. C. 2004. Albicidin pathotoxin produced by Xanthomonas albilineans is encoded by three large PKS and NRPS genes present in a gene cluster also containing several putative modifying, regulatory, and resistance genes. Mol. Plant-Microbe Interact. 17:414-427.

Schwarzer, D., Finking, R., and Marahiel, M. A. 2003. Nonribosomal peptides: From genes to products. Nat. Prod. Rep. 20:275-287.

Simon, R., Priefer, U., and Puhler, A. 1983. A broad-host range mobilization system for in vivo genetic engineering: Transposon mutagenesis in gram-negative bacteria. BioTechnology 1:784-791.

Stachelhaus, T., Mootz, H. D., and Marahiel, M. A. 1999. The specificityconferring code of adenylation domains in nonribosomal peptide synthetases. Chem. Biol. 6:493-505.

Staphorst, J. L., van Zyl, F. G. H., Strijdom, B. W., and Groenewold, Z. E. 1985. Agrocin-producing pathogenic and nonpathogenic biotype-3 strains of Agrobacterium tumefaciens active against biotype-3 pathogens. Curr. Microbiol. 12:45-52.

Walsh, C. T., Gehring, A. M., Weinreb, P. H., Quadri, L. E., and Flugel, R. S. 1997. Post-translational modification of polyketide and nonribosomal peptide synthases. Curr. Opin. Chem. Biol. 1:309-315.

Wang, N., Lu, S. E., Wang, J., Chen, Z. J., and Gross, D. C. 2006. The expression of genes encoding lipodepsipeptide phytotoxins by Pseudomonas syringae pv. syringae is coordinated in response to plant signal molecules. Mol. Plant-Microbe Interact. 19:257-269.

Wang, R. F., and Kushner, S. R. 1991. Construction of versatile low-copynumber vectors for cloning, sequencing and gene expression in Escherichia coli. Gene 100:195-199.

Weber, G., Schörgendorfer, K., Schneider-Scherzer, E., and Leitner, E. 1994. The peptide synthetase catalyzing cyclosporin production in Polycladium niveum is encoded by a giant 45.8-kilobase open reading frame. Curr. Genet. 26:120-125.

Yan, A., Wang, X. L., Zhang, X. H., and Xu, Y. Q. 2007. LysR family factor PltR positively regulates Pyoluteorin production in a pathway-specific manner in Pseudomonas sp. M18. Sci. China Ser. C-Life Sci. 50:518-524.

Zheng, D., Zhang, H. S., Carle, S., Hao, G. X., Holden, M. R., and Burr, T. J. 2003. A luxR homolog, aviR, in Agrobacterium vitis is associated with induction of necrosis on grape and a hypersensitive response on tobacco. Mol. Plant-Microbe Interact. 16:650-658.

Zheng, D., Hao, G., Cursino, L., Zhang, H., and Burr, T. J. 2012. LhnR and upstream operon LhnABC in Agrobacterium vitis regulate the induction of tobacco hypersensitive responses, grape necrosis and swarming motility. Mol. Plant Pathol. 13:641-652.

\section{AUTHOR-RECOMMENDED INTERNET RESOURCE}

Virginia Tech and Virginia Bioinformatics Institute's A. vitis genome: agro.vbi.vt.edu/public 